\title{
Desempenho de mudas de mirtilo obtidas por micropropagação ou estaquia
}

\author{
André Luiz Kulkamp de Souza(1), Márcia Wulff Schuch(1), Luís Eduardo Corrêa Antunes ${ }^{(2)}$, \\ Juliano Dutra Schmitz ${ }^{(1)}$, Mateus da Silveira Pasa(1), Samila Silva Camargo ${ }^{(1)}$ e Bruno Carra ${ }^{(1)}$
}

(1)Universidade Federal de Pelotas, Departamento de Fitotecnia, Caixa Postal 354, CEP 96010-900 Pelotas, RS. E-mail: andreluizks@yahoo.com.br, marciaws@ufpel.tche.br, jdsagro@gmail.com, mateus.pasa@gmail.com, samilasc@yahoo.com.br, brunocarra@gmail.com ${ }^{(2)}$ Embrapa Clima Temperado, Caixa Postal 403, CEP 96001-970 Pelotas, RS. E-mail: luis.eduardo@cpact.embrapa.br.

Resumo - O objetivo deste trabalho foi avaliar o desenvolvimento vegetativo e o início do período produtivo de mirtilos (Vaccinium virgatum) propagados por estaquia e micropropagação. No ano de 2009, foi implantado um pomar de mirtilo com mudas de um ano de idade, em espaçamento de 1,3x4,0 m. Utilizaram-se as cultivares Bluegem, Briteblue e Woodard, do grupo "rabbiteye". Foram avaliados os seguintes parâmetros: altura de planta, diâmetro e número de brotações, diâmetro médio dos frutos, frutos colhidos por planta, produção média por planta, produtividade estimada por hectare, massa de matéria fresca por fruto, teor de sólidos solúveis, acidez titulável e pH. Plantas obtidas pela técnica de micropropagação apresentaram maior crescimento vegetativo inicial, em razão do rejuvenescimento causado por este tipo de propagação. O método de propagação não influenciou a qualidade dos frutos. Ao contrário do esperado, as plantas micropropagadas não mostraram atraso no início da produção de frutos e apresentaram produtividade e qualidade de frutos semelhantes às de plantas propagadas por estaquia.

Termos para indexação: Vaccinium virgatum, juvenilidade, produção de mudas, propagação vegetativa, rejuvenescimento.

\section{Performance of blueberry seedlings obtained by micropropagation or cutting}

\begin{abstract}
The objective of this work was to evaluate the vegetative development and the onset of the productive period of blueberry (Vaccinium virgatum) seedlings obtained by semi-hardwood cuttings or micropropagation. In 2009, a blueberry orchard was established with one-year-old seedlings, at $1.3 \times 4.0 \mathrm{~m}$ spacing. The cultivars Bluegem, Briteblue, and Woodard, from the rabbiteye group were utilized. The following parameters were evaluated: plant height, number and diameter of shoot, berry average diameter, number of harvested fruit per plant, average production per tree, estimated yield by hectare, fresh matter per fruit, content of soluble solids, titratable acidity and $\mathrm{pH}$. Plants originated from the micropropagation technique showed high rate of initial vegetative growth, due to the rejuvenation caused by this sort of propagation. Propagation methods did not affect fruit quality. Despite the expected, micropropagated plants showed no delay in the initial fruit production and its fruit yield and quality were similar to those of cutting-propagated plants.
\end{abstract}

Index terms: Vaccinium virgatum, juvenility, seedling production, vegetative propagation, rejuvenation.

\section{Introdução}

O plantio do mirtilo tem crescido significativamente (Brazelton \& Strik, 2007), e a perspectiva é que esse crescimento continue (Strik, 2006). No Brasil, a cultura é recente, mas está em ascensão, principalmente na região Sul do País (Bañados, 2006).

Um dos principais problemas observados nesse cultivo, no Brasil, é a produção de mudas, limitada pela dificuldade de propagação da maioria das cultivares (Wagner Júnior et al., 2004). Comercialmente, as mudas são produzidas por meio de estaquia herbácea e semilenhosa, em casa de vegetação, com sistema de nebulização intermitente e controle de temperatura e umidade relativa. Além disso, uma das técnicas utilizadas com eficiência, para disponibilizar mudas de mirtilo no mercado, tem sido a micropropagação (Miller et al., 2006; Albert et al., 2009).

O desenvolvimento de mudas oriundas de diferentes métodos de propagação, em condições de campo, tem sido estudado em fruteiras como oliveira (Bati et al., 2006), pessegueiro (Marín et al., 2003), bananeira (Álvares \& Caldas, 2002), mamoeiro (Talavera et al., 2009), entre outros. Na cultura do mirtilo, os resultados têm variado entre cultivares, grupos e locais de realização dos experimentos. Ao trabalhar com a cultivar Northblue, em campo, Read et al. (1989) 
e Litwinczuk et al. (2005) observaram que plantas micropropagadas tiveram maior crescimento vegetativo, enquanto Albert et al. (2009) constataram maior crescimento vegetativo em mudas propagadas por estaquia. Litwinczuk et al. (2005), no entanto, constataram que mirtilos micropropagados floresceram com um ano de atraso, em consequência do rejuvenescimento causado pelo sucessivo número de subcultivos in vitro. Embora esse rejuvenescimento possa aumentar o vigor das plantas e auxiliar no desenvolvimento vegetativo, o comportamento pós-plantio dessas mudas ainda causa preocupação entre viveiristas e produtores, em razão do possível atraso na entrada em produção das plantas.

O objetivo deste trabalho foi avaliar o desenvolvimento vegetativo e o início do período produtivo, em campo, de mirtilos propagados por estaquia e micropropagação.

\section{Material e Métodos}

O experimento foi realizado na Fazenda Agropecuária da Palma, Município de Capão do Leão, RS, pertencente à Universidade Federal de

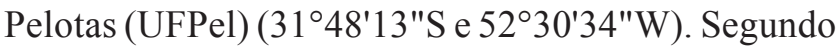
classificação de Köppen, a região de Pelotas apresenta clima do tipo Cfa, com temperatura média anual de $17,8^{\circ} \mathrm{C}$, umidade relativa média anual de $80,7 \%$, precipitação pluvial média anual de $1.366,9 \mathrm{~mm}$ (Agrometeorologia, 2011).

O plantio foi realizado no dia 21 de agosto de 2009, em delineamento de blocos ao acaso, com arranjo fatorial $3 \times 2$, com três cultivares de mirtilo (Bluegem, Briteblue e Woodard) e dois métodos de propagação (in vitro e estaquia), no total de seis tratamentos, com cinco repetições cada, com cada parcela constituída por quatro plantas.

As mudas micropropagadas foram produzidas pelo Laboratório de Propagação de Plantas Frutíferas, da UFPel, obtidas em meio nutritivo WPM ("wood plant media") acrescido de $100 \mathrm{mg} \mathrm{L}^{-1}$ de mioinositol, $30 \mathrm{~g} \mathrm{~L}^{-1}$ de sacarose e $6 \mathrm{~g} \mathrm{~L}^{-1}$ de ágar, além de $5 \mathrm{mg}$ de 2iP (citocinina) adicionados na fase de multiplicação (Schuch et al., 2008). O enraizamento foi realizado ex-vitro, em casa de vegetação com temperatura controlada de aproximadamente $25^{\circ} \mathrm{C}$, seguido de aclimatização em substrato à base de Plantmax e vermiculita média, pelo período de um ano, em sacos de polietileno preto de 1,5 L. Diariamente, as plantas foram irrigadas com água a $\mathrm{pH} 5,0 \mathrm{e}$, a cada 15 dias, foram aplicados $100 \mathrm{~mL}$ de solução nutritiva, composta por: $0,2 \mathrm{mg} \mathrm{L}^{-1}$ de sulfato de amônio; $0,75 \mathrm{mg} \mathrm{L}^{-1} \mathrm{de}$ magnésio; $0,35 \mathrm{mg} \mathrm{L}^{-1}$ de potássio; $0,3 \mathrm{mg} \mathrm{L}^{-1} \mathrm{de}$ ureia; e $0,25 \mathrm{mg} \mathrm{L}^{-1}$ de ácido fosfórico. As mudas utilizadas apresentavam aproximadamente dez subcultivos, número considerado adequado para que não ocorra variação somaclonal (Albert et al., 2009). As mudas micropropagadas tinham um ano desde seu transplante em sacos de plástico com substrato até o plantio em campo.

As mudas propagadas por estaquia foram obtidas a partir de segmentos semilenhosos que continham de quatro a cinco gemas, com diâmetro médio de $6 \mathrm{~mm}$, sem folhas na base e com duas folhas, cortadas pela metade, na extremidade superior das estacas. Foram realizadas lesões superficiais de aproximadamente $1 \mathrm{~cm}$, na base dos propágulos, para que houvesse maior absorção de água e do fitorregulador ácido indolbutírico (AIB), que foi utilizado à concentração de $1.000 \mathrm{mg} \mathrm{L}^{-1}$, em imersão por $15 \mathrm{~s}$. As estacas foram colocadas para enraizar em estufa a $25^{\circ} \mathrm{C}$, por 60 dias, com sistema de nebulização intermitente para manter a umidade relativa próxima a $90 \%$, seguida da aclimatização sob tela de sombreamento $(60 \%)$ até que a muda tivesse um ano de idade.

O solo foi preparado na forma de camalhões, para atenuar o acúmulo de água próximo ao sistema radicular; a adubação foi baseada em análise de solo e em recomendação do Manual de adubação e calagem (Sociedade Brasileira de Ciência do Solo, 2004). No momento da implantação do pomar, aplicou-se superfosfato simples $\left(150 \mathrm{~kg} \mathrm{ha}^{-1}\right)$, para corrigir a deficiência de $\mathrm{P}$, e $24 \mathrm{Mg} \mathrm{ha}^{-1}$ de esterco curtido de bovino, para aumentar o teor de matéria orgânica, e melhorar os atributos físicos e biológicos do solo. A adubação nitrogenada foi dividida em três partes, aplicadas à época da floração (início, plena e fim), com $20 \mathrm{~g}$ de $\mathrm{N}$ por planta, tendo-se usado como fonte $\mathrm{o}$ sulfato de amônio.

O pomar foi conduzido em espaçamento de 1,3x4,0 m, com irrigação por gotejamento e cobertura natural do solo com acícula de pinus, para diminuir incidência de plantas daninhas e manter a umidade. O solo foi classificado como Argissolo Amarelo eutrófico típico, de acordo com o Sistema Brasileiro de Classificação, e apresentou pH 5,0 e textura arenosa: 
$67,5 \%$ de areia, $13,6 \%$ de silte, $18,8 \%$ de argila e $1,7 \%$ de matéria orgânica.

Logo após o plantio, foi realizada a poda de formação das plantas por meio do rebaixamento das hastes, com a retirada das gemas florais, para estimular a brotação de novas hastes e formar a arquitetura da planta.

As seguintes variáveis de crescimento vegetativo foram avaliadas em julho de 2010: altura de planta, e diâmetro e número de brotações da base da planta. A avaliação do desenvolvimento vegetativo, realizada na primeira estação de crescimento após o plantio, permite determinar um possível efeito de rejuvenescimento do material micropropagado.

$\mathrm{O}$ incremento da altura da planta foi medido do solo até o ápice do ramo de maior tamanho, tendo-se subtraído a altura medida no momento da instalação do experimento. $\mathrm{O}$ diâmetro das brotações foi determinado com o uso de paquímetro digital, à altura de $10 \mathrm{~cm}$ do solo, tendo-se considerado apenas o incremento em relação ao diâmetro da época de plantio. Para o surgimento de novas brotações, foram consideradas as que vieram da base da planta.

Os frutos foram colhidos de 19/11/2010 a 20/1/2011, 455 dias após o transplantio, no estágio de maturação completa, com coloração violeta em todo o fruto e presença de pruína. Foram realizadas as seguintes avaliações de produção: massa de matéria fresca dos frutos (MFF, g), frutos colhidos por planta (FCP), produção média por planta (PMP, kg) e produção estimada por hectare $\left(\mathrm{PEH}, \mathrm{kg} \mathrm{ha}^{-1}\right)$. Para as avaliações de diâmetro médio dos frutos (DMF, $\mathrm{mm}$ ), teor de sólidos solúveis ( $\mathrm{SS}, \%$ ), pH e acidez titulável (AT, meq por $100 \mathrm{~mL}$ ), foram retiradas amostras aleatórias de 100 frutos por repetição. O diâmetro médio dos frutos foi medido em seu sentido equatorial, com paquímetro digital, 150 mm/6, (Digimess, São Paulo, SP, Brasil). Os teores de sólidos solúveis foram determinados com refratômetro digital, com compensação automática de temperatura, PAL-1, (Atago, Tókio, Japão). A medição de $\mathrm{pH}$ e acidez titulável foi realizada conforme normas do Instituto Adolfo Lutz (Pregnolatto \& Pregnolatto, 1985), o pH em pHmetro digital, PHS-3B, (Phtek, Curitiba, PR, Brasil), e a AT por meio de titulação de $10 \mathrm{~mL}$ de suco, diluídos em $100 \mathrm{~mL}$ de água destilada com hidróxido de sódio $0,1 \mathrm{~N}$, até pH 8,1.

Os dados foram submetidos à análise de variância, e a comparação de médias dos tratamentos foi feita pelo teste de Tukey, a $5 \%$ de probabilidade.

\section{Resultados e Discussão}

A propagação in vitro foi a que induziu maior crescimento vegetativo inicial, representada pela maior altura de planta e diâmetro de brotações (Tabela 1). Resultados semelhantes, quanto ao maior vigor de plantas micropropagadas, foram encontrados por Litwinczuk et al. (2005). Essa resposta está relacionada à maior juvenilidade das mudas propagadas in vitro, já que essa técnica faz com que a planta seja trazida de um estado maduro para um estado juvenil (rejuvenescimento), retomando a capacidade de enraizamento e o vigor do crescimento vegetativo (Wendling \& Xavier, 2001). De acordo com Schuch et al. (2008), a micropropagação de mirtilo 'Climax' com sucessivas repicagens e cultivos em presença de citocinina mostra elevada capacidade de rejuvenescimento in vitro do material adulto e pode ser comparada à propagação de plantas obtidas de sementes, tanto na capacidade de emitir novas brotações, quanto no número de gemas e taxa de multiplicação.

Ese comportamento também é notado em outras espécies lenhosas como o eucalipto, em que Santos et al. (2005) constataram maior crescimento em altura e diâmetro de plantas em campo, induzido por micropropagação. O estádio juvenil possibilita maior crescimento vegetativo da planta e a produção de grande área foliar, como também maior produção de fotoassimilados a serem, posteriormente, utilizados no desenvolvimento dos frutos e do sistema radicular (Greenwood \& Hutchison, 1993). Morrison et al. (2000), ao trabalhar com resultados obtidos no ano posterior ao plantio em campo, concluíram que o período de um ano é suficiente para constatar maior vigor nas plantas micropropagadas, em comparação às provenientes de estaquia.

Considerando-se as diferenças obtidas entre as cultivares, observou-se maior altura de 'Briteblue' em comparação à 'Bluegem', que não diferiu significativamente de 'Woodard' (Tabela 1). Quanto ao diâmetro das brotações, não se verificou diferença significativa entre as cultivares.

Quanto à variável número de brotações vindas do colo da planta, constatou-se que não houve diferença significativa entre as diferentes cultivares propagadas por estaquia; mas, entre as plantas propagadas in vitro, houve maior número de brotações em 'Woodard', seguida por 'Bluegem' e 'Briteblue' (Tabela 2). 
Vários autores comprovaram, em campo, que mudas de mirtilo propagadas in vitro apresentam maior número de brotações do que as propagadas por estaquia (Read et al., 1989; Jamieson \& Nickerson, 2003; Litwinczuk et al., 2005). A emissão de maior número de brotações oriundas do colo da planta possibilita renovação das hastes produtivas, já que o mirtilo apresenta hábito basitônico, ou seja, suas brotações surgem da base da planta. Esse atributo faz com que sejam facilmente notadas diferenças no hábito de crescimento das plantas propagadas in vitro, com maior número de hastes principais e taxa de crescimento (Smagula, 2006).

Para as variáveis produção por planta e por hectare, diâmetro dos frutos e número de frutos colhidos por planta não foi constatada diferença significativa entre os métodos de propagação (Tabelas 1 e 2). Esse comportamento indica que, nas condições do experimento, o rejuvenescimento oriundo da micropropagação não impediu a formação de gemas de flor e a consequente produção de frutos, no ano seguinte à implantação do pomar. Esse resultado contraria os de Litwinczuk et al. (2005), que trabalharam com mirtilo 'Herbert' e afirmaram que uma das limitações do uso comercial da micropropagação, independentemente do número de subcultivos, está no longo período de juvenilidade após o plantio em campo, causado pelo rejuvenescimento proporcionado pelas várias repicagens do material (Schuch \& Erig, 2005). Assim, era esperado que essas plantas entrassem em produção depois das obtidas por estaquia, já que, enquanto juvenis, a iniciação floral e a floração não podem ser induzidas, mesmo que as condições externas sejam favoráveis (Xavier et al., 2009). Esse comportamento mostra que o rejuvenescimento foi capaz de auxiliar o crescimento vegetativo, porém não retardou a floração e a frutificação. Provavelmente, isso se deve a um limite adequado de subcultivos. Albert et al. (2009) obtiveram bons resultados com o mesmo número de subcultivos usado neste trabalho.

Nas et al. (2003) sugerem que plantas de videira, aveleira e castanheira micropropagadas podem manter sua maturidade fisiológica durante o crescimento in vitro ou retomá-la logo após a saída desta condição. Dessa forma, elas podem frutificar junto com as propagadas de maneira convencional, em campo. De acordo com Smulders \& Klerk (2011), o rejuvenescimento é consequência de uma variação epigenética, já que as plantas, quando estabelecidas

Tabela 1. Altura de planta, diâmetro de brotações e de frutos, número de frutos por planta e produção por planta e por área de plantas de mirtilo 'Bluegem', 'Briteblue' e 'Woodard', micropropagadas e propagadas por estaquia semilenhosa ${ }^{(1)}$.

\begin{tabular}{|c|c|c|c|c|c|c|}
\hline \multirow[t]{2}{*}{ Tratamento } & \multirow{2}{*}{$\begin{array}{l}\text { Altura } \\
(\mathrm{cm})\end{array}$} & \multicolumn{2}{|c|}{ Diâmetro (mm) } & \multirow{2}{*}{$\begin{array}{c}\text { Frutos por } \\
\text { planta }\end{array}$} & \multicolumn{2}{|c|}{ Produção (kg) } \\
\hline & & Brotação & Frutos & & Planta & Hectare \\
\hline & \multicolumn{6}{|c|}{ Propagação } \\
\hline Micropropagação & $42,93 a$ & $9,60 \mathrm{a}$ & 14,08 & 554 & 0,75 & 1.438 \\
\hline \multirow[t]{2}{*}{ Estaquia } & $25,34 \mathrm{~b}$ & $7,32 \mathrm{~b}$ & 13,97 & 484 & 0,66 & 1.269 \\
\hline & \multicolumn{6}{|c|}{ Cultivar } \\
\hline Briteblue & $39,87 \mathrm{a}$ & 9,51 & $13,48 b$ & $671 \mathrm{a}$ & $0,89 \mathrm{a}$ & $1.715 \mathrm{a}$ \\
\hline Woodard & $33,96 \mathrm{ab}$ & 7,39 & $14,61 \mathrm{a}$ & $633 a$ & $0,89 \mathrm{a}$ & $1.706 \mathrm{a}$ \\
\hline Bluegem & $28,58 \mathrm{~b}$ & 8,48 & $14,00 \mathrm{ab}$ & $253 \mathrm{~b}$ & $0,33 \mathrm{~b}$ & $638 \mathrm{~b}$ \\
\hline CV (\%) & 21,85 & 22,80 & 3,97 & 63 & 63 & 63 \\
\hline
\end{tabular}

${ }^{(1)}$ Médias seguidas por letras iguais, nas colunas, não diferem pelo teste de Tukey, a 5\% de probabilidade.

Tabela 2. Número de brotações, massa de matéria fresca por fruto, teor de sólidos solúveis, acidez titulável e pH de frutos de cultivares de mirtilo propagadas pelos métodos de estaquia e micropropagação (Microp. (1) $^{(1)}$.

\begin{tabular}{|c|c|c|c|c|c|c|c|c|c|c|}
\hline \multirow[t]{2}{*}{ Cultivar } & \multicolumn{2}{|c|}{ Brotações } & \multicolumn{2}{|c|}{ Massa por fruto } & \multicolumn{2}{|c|}{ Sólidos solúveis } & \multicolumn{2}{|c|}{ Acidez titulável (meq por $100 \mathrm{~mL}$ ) } & \multicolumn{2}{|c|}{$\mathrm{pH}$} \\
\hline & Estaquia & Microp. & Estaquia & Microp. & Estaquia & Microp. & Estaquia & Microp. & Estaquia & Microp. \\
\hline Bluegem & $1,70 \mathrm{aB}$ & $4,30 \mathrm{cA}$ & $1,31 \mathrm{aA}$ & $1,31 \mathrm{abA}$ & $12,40 \mathrm{aA}$ & $12,16 \mathrm{aA}$ & $9,90 \mathrm{bA}$ & $9,50 \mathrm{bA}$ & $2,74 \mathrm{aA}$ & $2,71 \mathrm{aA}$ \\
\hline Woodard & $2,02 \mathrm{aB}$ & $9,07 \mathrm{aA}$ & $1,37 \mathrm{aA}$ & $1,44 \mathrm{aA}$ & $11,56 \mathrm{abA}$ & $11,76 \mathrm{aA}$ & $12,28 \mathrm{aA}$ & $10,55 \mathrm{aB}$ & $2,44 \mathrm{bA}$ & $2,48 \mathrm{bA}$ \\
\hline Britleblue & $2,25 \mathrm{aB}$ & $6,33 \mathrm{bA}$ & $1,47 \mathrm{aA}$ & $1,21 \mathrm{bB}$ & $10,90 \mathrm{bB}$ & $12,96 \mathrm{aA}$ & $10,53 \mathrm{bA}$ & $10,60 \mathrm{aA}$ & $2,74 \mathrm{aA}$ & $2,53 \mathrm{bB}$ \\
\hline CV $(\%)$ & \multicolumn{2}{|c|}{23,28} & \multicolumn{2}{|c|}{7,99} & \multicolumn{2}{|c|}{7,68} & \multicolumn{2}{|c|}{5,72} & \multicolumn{2}{|c|}{1,38} \\
\hline
\end{tabular}

${ }^{(1)}$ Médias seguidas por letras iguais, minúsculas nas colunas e maiúsculas nas linhas, em uma mesma variável, não diferem pelo teste de Tukey, a 5\% de probabilidade. 
in vitro, sofrem uma situação de estresse e crescem sob condições bem diferentes das naturais (Molinier et al., 2006; Van Staden et al., 2006; Desjardins et al., 2009). Esse tipo de alteração, ao contrário da variação somaclonal, é temporária, o que torna possível a reversão após algum tempo (Bairu \& Kane, 2011).

A cultivar Woodard foi a que apresentou maiores diâmetros, sem que tenha diferido significativamente Briteblue (Tabela 1). A cultivar Bluegem foi a de menor diâmetro. As cultivares Bluegem e Woodard se destacaram quanto à produção por planta e por área, tendo atingido valores tidos como adequados (Read et al., 1989), considerando-se que esta foi a primeira colheita. Os menores índices de produtividade para 'Briteblue' se devem a problemas de ordem fitossanitária, como a seca dos ramos ("stem blight"), causada por Botryosphaeria spp.. Antunes et al. (2008) constataram produção de $1,5,1,63$ e $0,67 \mathrm{~kg}$ por planta, respectivamente, para as cultivares Bluegem, Briteblue e Woodard, oriundas de estaquia. Marín et al. (2003) verificaram que, de modo geral, o método de propagação não influencia o desempenho em campo de mudas de pessegueiro, propagadas in vitro e por estaquia, uma vez que não foram observadas diferenças significativas quanto aos caracteres produção, sólidos solúveis, acidez titulável e $\mathrm{pH}$.

No que diz respeito à massa de matéria fresca por fruto e ao teor de sólidos solúveis, não houve diferença significativa entre as cultivares Bluegem e Woodard (Tabela 2). Morrison et al. (2000) observaram resultados semelhantes em mirtilos "lowbush". Para 'Briteblue', houve menor massa de matéria fresca e maior teor de sólidos solúveis nos frutos de plantas micropropagadas, o que pode ser explicado pela diluição desses componentes em um maior volume de fruto. A massa de matéria fresca dos frutos foi pouco influenciada pela cultivar; porém, sabe-se que, em frutíferas, um maior número de frutos colhidos por planta implica em frutos de menor massa de matéria fresca, em razão da maior competição por fotoassimilados, conforme encontrado em estudos com lichia (Santos et al., 2009). Frutos da cultivar Briteblue obtida por estaquia apresentaram maior massa de matéria fresca, em comparação aos da planta propagada in vitro, e ocorreram em menor quantidade, já que esse tratamento, mesmo com os frutos maiores, foi o que atingiu menor produção por planta.
Entre as plantas provenientes de estaquia, os maiores teores de sólidos solúveis foram verificados em 'Bluegem', que diferiram significativamente de 'Briteblue' (Tabela 2). Nas plantas micropropagadas, no entanto, não foi observado o mesmo comportamento, e todos os tratamentos foram estatisticamente iguais. Em estudos com 'Bluegem', Brackmann et al. (2010) obtiveram, no momento da colheita, teores de sólidos solúveis de $11,7 \%$ e 10,48 meq $100 \mathrm{~mL}^{-1}$ de acidez titulável, semelhantes ao encontrado no presente trabalho.

Os valores de acidez titulável e pH (Tabela 2) foram os esperados para frutos de mirtilo do grupo "rabbiteye" (Moraes et al., 2007). A cultivar Woodard apresentou maior acidez titulável, tanto em frutos oriundos da estaquia, quanto nos da micropropagação. A maior acidez dessa cultivar pode ser comprovada pelo valor de pH mais baixo, em comparação ao das demais cultivares. Em relação ao pH, notou-se diferença entre os métodos de propagação apenas para 'Briteblue', em que foi possível constatar menor valor nos frutos de plantas micropropagadas. Essa resposta pode ser explicada pela existência de maior proporção de casca em relação à polpa (Giovanelli \& Buratti, 2009), já que esses frutos tiveram menor tamanho, mostrado pela sua menor massa de matéria fresca.

\section{Conclusões}

1. Mirtilos micropropagados apresentam, em campo, crescimento vegetativo inicial superior, comparado aos propagados por estaquia.

2. O método de propagação não apresenta influência sobre a produção e a qualidade dos frutos de mirtilo 'Bluegem', 'Briteblue' e 'Woodard', no primeiro ano de produção.

3. O rejuvenescimento obtido pela micropropagação é revertido no primeiro ano pós-plantio, e as plantas micropropagadas não mostram atraso no início da produção de frutos, em comparação às propagadas por estaquia.

\section{Agradecimentos}

Ao Conselho Nacional de Desenvolvimento Científico e Tecnológico e à Coordenação de Aperfeiçoamento de Pessoal de Nível Superior, pelo apoio e bolsas concedidas. 


\section{Referências}

AGROMETEOROLOGIA - FAEM / UFPEL: normais climatológicas mensais do período 1971/2000. Disponível em: $<$ http://www.ufpel.edu.br/faem/agrometeorologia/normais.htm>. Acesso em: 10 ago. 2011.

ALBERT, T.; STARAST, M.; KARP, K.; KALDMÄE, H.; VOOL, E.; PAAL, T. The influence of propagation method on growth of the half-highbush blueberry 'Northblue'. Acta Horticulturae, v.812, p.141-146, 2009.

ÁlVARES, M. do C.; CALDAS, L.S. Crescimento, produção e variação somaclonal em bananeiras micropropagadas. Pesquisa Agropecuária Brasileira, v.37, p.415-420, 2002.

ANTUNES, L.E.C.; GONÇALVES, E.D.; RISTOW, N.C.; CARPENEDO, S.; TREVISAN, R. Fenologia, produção e qualidade de frutos de mirtilo. Pesquisa Agropecuária Brasileira, v.43, p.1011-1015, 2008.

BAIRU, M.W.; KANE, M.E. Physiological and developmental problems encountered by in vitro cultured plants. Plant Growth Regulation, v.63, p.101-103, 2011.

BAÑADOS, M.P. Blueberry production in South America. Acta Horticulturae, v.715, p.165-172, 2006.

BATI, C.B.; GODINO, G.; MONARDO, D.; NUZZO, V. Influence of propagation techniques on growth and yield of olive tree cultivars 'Carolea' and 'Nocellara Etnea'. Scientia Horticulturae, v.109, p.173-182, 2006.

BRACKMANN, A.; WEBER, A.; GIEHL, R.F.H.; EISERMANN, A.C.; SAUTTER, C.K.; GONÇALVES, E.D.; ANTUNES, L.E.C. Armazenamento de mirtilo 'Bluegem' em atmosfera controlada e refrigerada com absorção e inibição de etileno. Revista Ceres, v.57, p.6-11, 2010.

BRAZELTON, D.; STRIK, B.C. Perspective on the U.S. and global blueberry industry. Journal of the American Pomological Society, v.61, p.144-147, 2007.

DESJARDINS, Y.; DUBUC, J.F.; BADR, A. In vitro culture of plants: a stressful activity. Acta Horticulturae, v.812, p.29-50, 2009.

GIOVANELLI, G.; BURATTI, S. Comparison of polyphenolic composition and antioxidant activity of wild Italian blueberries and some cultivated varieties. Food Chemistry, v.112, p.903-908, 2009.

GREENWOOD, M.S.; HUTCHISON, K.W. Maturation as a developmental process. In: AHUJA, M.R.; LIBBY, W.J. (Ed.). Clonal forestry: genetics and biotechnology. Budapest: Springer-Verlag, 1993. p.14-33.

JAMIESON, A.R.; NICKERSON, N.L. Field performance of the lowbush blueberry propagated by seed, stem cuttings and micropropagation. Acta Horticulturae, v.626, p.431-436, 2003.

LITWINCZUK, W.; SZCZERBA, G.; WRONA, D. Field performance of highbush blueberries (Vaccinium x corymbosum L.) cv. 'Herbert' propagated by cuttings and tissue culture. Scientia Horticulturae, v.106, p.162-169, 2005.
MARÍN, J.A.; CASTILLO, M.; GARCÍA, E.; ANDREU P. Field performance of grafted fruit-tree rootstocks was not affected by micropropagation. Acta Horticulturae, v.616, p.295-299, 2003.

MILlER, S.; RAWNSley, E.; GEORGE, J.; PATEL, N. A comparison of blueberry propagation techniques used in New Zealand. Acta Horticulturae, v.715, p.397-402, 2006.

MOLINIER, J.; RIES, G.; ZIPFEL, C.; HOHN, B. Transgeneration memory of stress in plants. Nature, v.442, p.1046-1049, 2006.

MORAES, J.O. de; PERTUZATTI, P.B.; CORRÊA, F.V.; SALAS-MELLADO, M. de Las M. Estudo do mirtilo (Vaccinium ashei Reade) no processamento de produtos alimentícios. Ciência e Tecnologia de Alimentos, v.27, p.18-22, 2007.

MORRISON, S.; SMAGULA, J.M.; LITTEN, W. Morphology, growth, and rhizome development of Vaccinium angustifolium Ait. seedlings, rooted softwood cuttings, and micropropagated plantlets. HortScience, v.35, p.738-741, 2000.

NAS, M.N.; READ, P.E.; MILLER, V.; RUTTER, P.A. In vitro "rejuvenation" of woody species is temporary. Acta Horticulturae, v.625, p.211-215, 2003.

PREGNOLATTO, W.; PREGNOLATTO, N.P. (Coord.). Normas analíticas do Instituto Adolfo Lutz: métodos químicos e físicos para análise de alimentos. 3.ed. São Paulo: Instituto Adolfo Lutz, 1985. v.1., 553p.

READ, P.E.; WILDUNG, D.K.; HARTLEY, C.A. Field performance of in vitro propagated 'Northblue' blueberries. Acta Horticulturae, v.241, 191-194, 1989.

SANTOS, A.P. dos; XAVIER, A.; OLIVEIRA, M.L. de; REIS, G.G. Efeito da estaquia, miniestaquia, microestaquia e micropropagação no desempenho silvicultural de clones de Eucalyptus grandis. Scientia Forestalis, n.68, p.29-38, 2005.

SANTOS, C.E.M. dos; SILVA, J.O. da C. e; CAVATTE, R. da P.Q.; SALOMÃO, L.C.C.; BRUCKNER, C.H. Raleio de frutos em lichieira 'Bengal'. Revista Brasileira de Fruticultura, v.31, p.588-592, 2009.

SCHUCH, M.W.; DAMIANI, C.R.; SILVA, L.C. da; ERIG, A.L. Micropropagação como técnica de rejuvenescimento em mirtilo (Vaccinium ashei Reade) cultivar Clímax. Ciência Agrotécnica, v.32, p.814-820, 2008.

SCHUCH,M.W.; ERIG,A.C. Micropropagação de plantas frutíferas. In: FACHINELLO, J.C.; HOFFMANN, A.; NACHTIGAL, J.C. (Ed.). Propagação de plantas frutíferas. Brasília: Embrapa Informação Tecnológica; Bento Gonçalves: Embrapa Uva e Vinho, 2005. p.155-173.

SMAGULA, J.M.J. Tissue culture propagation. In: CHILDERS, N.F.; LYRENE, P.M. (Ed.). Blueberries: for growers, gardeners, promoters. Florida: E.O. Painter Printing Company, 2006. p.55-58.

SMULDERS, M.J.M.; KLERK, G.J. de. Epigenetics in plant tissue culture. Plant Growth Regulation, v.63, p.137-146, 2011.

SOCIEDADE BRASILEIRA DE CIÊNCIA DO SOLO. Comissão de Fertilidade do Solo - RS/SC. Recomendação de adubação e calagem para os estados do Rio Grande do Sul e Santa Catarina. 3.ed. Passo Fundo: SBCS, 2004. 223p. 
STRIK, B. Blueberry production and research trends in North America. Acta Horticulturae, v.715, p.173-184, 2006.

TALAVERA, C.; ESPADAS, F.; CONTRERAS, F.; FUENTES, G.; SANTAMARÍA, J.M. Acclimatization, rooting and field establishment of micropropagated papaya plants. Acta Horticulturae, v.812, p.373-378, 2009.

VAN STADEN, J.; FENNELL, C.W.; TAYLOR, N.J. Plant stress in vitro: the role of phytohormones. Acta Horticulturae, v.725, p.55-61, 2006.
WAGNER JÚNIOR, A.; COUTO, M.; RASEIRA, M. do C.B.; FRANZON, R.C. Efeito da lesão basal e do ácido indolbutírico no enraizamento de estacas herbáceas de quatro cultivares de mirtilo. Revista Brasileira de Agrociência, v.10, p.251-253, 2004.

WENDLING, I.; XAVIER, A. Gradiente de maturação e rejuvenescimento aplicado em espécies florestais. Floresta e Ambiente, v.8, p.187-194, 2001.

XAVIER, A.; WENDLING, I.; SILVA, R.L. da. Silvicultura clonal: princípios e técnicas. Viçosa: UFV, 2009. 272p.

Recebido em 2 de maio de 2011 e aprovado em 3 de agosto de 2011 